\title{
ERp29 counteracts the suppression of malignancy mediated by endoplasmic reticulum stress and promotes the metastasis of colorectal cancer
}

\author{
LILI GUO $^{1,2^{*}}$, LILI MA ${ }^{1-3^{*}}$, CHAO LIU $^{4 *}$, YAN LEI $^{1,2}$, NA TANG $^{5}$, \\ YINGXIN HUANG ${ }^{1,2}$, GUAN HUANG ${ }^{1,2}$, DAZHOU LI ${ }^{1,2}$, QI WANG ${ }^{1,2}$, GUANGLONG LIU $^{1,2}$, \\ MINSHAN TANG ${ }^{1,2}$, ZHILIANG JING ${ }^{1,2}$ and YONGJIAN DENG ${ }^{1,2}$ \\ ${ }^{1}$ Department of Pathology, Nanfang Hospital and School of Basic Medical Sciences, Southern Medical University; \\ ${ }^{2}$ Guangdong Provincial Key Laboratory of Molecular Tumor Pathology, Guangzhou, Guangdong 510515; \\ ${ }^{3}$ Department of Cardiothoracic Surgery, Taishan City People's Hospital, Taishan, \\ Guangdong 529200; ${ }^{4}$ Department of Pathology and Laboratory Medicine, \\ Guangdong General Hospital and Guangdong Academy of Medical Sciences, \\ Guangzhou, Guangdong 510080; ${ }^{5}$ Department of Pathology, Shenzhen People's Hospital, \\ Second Clinical Medical College of Jinan University, Shenzhen, Guangdong 518020, P.R. China
}

Received July 29, 2018; Accepted November 29, 2018

DOI: $10.3892 /$ or.2018.6943

\begin{abstract}
Endoplasmic reticulum protein 29 (ERp29), an endoplasmic reticulum (ER) protein, participates in ER stress (ERS), but little is known about the association of ERp29 with ERS in the metastasis and prognosis of cancerous diseases. The present study revealed that ERp29 was important to ERS and interfered with the malignant behaviors of colorectal cancer (CRC). Experiments in in vitro and in animal models revealed that ERS inhibited the cell growth and suppressed the metastatic capacity of CRC cells, but ERp29 counteracted these effects. Furthermore, it was demonstrated that ERp29 recovered the migration and metastatic behaviors of CRC cells suppressed by ERS, mediated only when it combined with cullin5 (CUL5). ERp29 also relied on CUL5 to promote epithelial-mesenchymal
\end{abstract}

Correspondence to: Dr Yongjian Deng, Department of Pathology, Nanfang Hospital and School of Basic Medical Sciences, Southern Medical University, 1838 North Guangzhou Road, Guangzhou, Guangdong 510515, P.R. China

E-mail: dengyj@smu.edu.cn

${ }^{*}$ Contributed equally

Abbreviations: ER, endoplasmic reticulum; ERS, endoplasmic reticulum stress; ERp29, endoplasmic reticulum protein 29; CRC, colorectal cancer; EMT, epithelial-mesenchymal transition; TM, tunicamycin; 4-PBA, 4-phenylbutyric acid; CUL5, cullin5; hiERp29, overexpressed ERp29; SSR4, translocon-associated protein subunit delta; TBCA, tubulin-specific chaperone A; RPA2, replication protein A $32 \mathrm{kDa}$ subunit

Key words: endoplasmic reticulum protein 29, endoplasmic reticulum stress, colorectal cancer cells, CUL5, metastasis transition. From the immunohistochemical examination of CRC tissues, the high expression of ERp29 was revealed to predict the poor prognosis of $457 \mathrm{CRC}$ cases. The retrospective analysis of the clinicopathological data of patients with CRC was consistent with the results of the in vitro and in vivo experiments. Thus, ERp29 protected CRC cells from ERS-mediated reduction of malignancy to promote metastasis and may be a potential target of medical intervention for CRC therapy.

\section{Introduction}

Individuals with malignancies suffer from the stress of the cancerous disease whereas cells are affected by intracellular stress. In eukaryotic cells, the endoplasmic reticulum (ER) is important for the biosynthesis of organelles and assembly of proteins (1). This state, when the accumulation of misfolded or unfolded proteins exceeds the ability of the body to clear them, ER homeostasis imbalance [named ER stress (ERS)] occurs in order to deal with the intracellular microenvironment changes (2). The published data has revealed that ERS is closely associated with the occurrence and development of multiple diseases including rheumatic disease $(3)$, diabetes $(4,5)$ and prostate cancer (6). Endoplasmic reticulum protein 29 (ERp29) is a reserved protein in ER (7), and it has been suggested that ERp29 may be involved in the aggressive behaviors of cancer cells (8). One previous study demonstrated that a triple-protein signature, including ERp29, chloride intracellular channel 4 and second mitochondria-derived activator of caspases/direct IAP-binding protein with low PI, may predict the prognostic risk of colorectal cancer (9). However, the function of ERp29 in colorectal cancer (CRC) remains unclear; it is potentially associated with ERS and should be further clarified.

ERS has been receiving increasing attention in the study of cancer cells as it is considered to activate caspase-12-induced 
apoptosis $(10,11)$. Cancer development studies have revealed an increasing risk of hepatic tumorigenesis and the promotion of virus-associated nasopharyngeal carcinogenesis in cells with ERS $(12,13)$. ERp29, as a molecular chaperone protein, is distributed ubiquitously and abundantly in mammalian tissues and its predominant subcellular localization is in the rough ER $(14,15)$. Certain published data implies that ERp29 participates in ERS-associated cell reactivity. The exact function of ERp29 appears to be diverse, depending on the tissue and cell type. ERp29 deficiency may result in lower apoptosis sensitivity in the adult thyrocytes of ERp $29^{-/-}$mice during stress response (16). ERp29 presents a favorable function in breast cancer cell survival against doxorubicin-induced genotoxic stress and against ionizing radiation, and it also demonstrates resistance to radiation treatment in nasopharyngeal carcinoma and mouse intestinal epithelial cells (17-19). Molecular and phenotypic remodeling of epithelial-mesenchymal transition (EMT) revealed advanced malignancy with the loss of cell-cell junctions, acquired cellular motility and invasiveness (20). It is unclear whether ERp29 serves a function in the ERS-associated EMT of cancer. Therefore, it is necessary to denote the function of ERp29 in CRC, in particular in its malignancy and aggressiveness during ERS.

The present study investigated whether ERp29 during ERS was involved in interfering with the malignant behaviors of $\mathrm{CRC}$, as well as its possible mechanisms. This was achieved by constructing an ERS model in CRC cell lines using conditioned media supplemented with tunicamycin (TM) and 4-phenylbutyric acid (4-PBA), as previously described by Reiling et al (21) and Kim et al (22), thus demonstrating a novel function of ERp29 during ERS in regulating malignant behaviors of CRC cells.

\section{Materials and methods}

Cell culture and treatment. All cell lines (SW620, HCT116, HT29, LS174T, SW480, LOVO and DLD1) were purchased from American Type Culture Collection (Manassas, VA, USA). Cells were cultured in RPMI-1640 (Gibco; Thermo Fisher Scientific, Inc., Waltham, MA, USA) containing $10 \%$ fetal bovine serum (Gibco; Thermo Fisher Scientific, Inc.) and incubated at $37^{\circ} \mathrm{C}$ in a $5 \% \mathrm{CO}_{2}$ incubator. Cancer cells were inoculated into a 6 -well plate overnight, then the medium was replaced with a new basal medium containing TM (Beijing Solarbio Science \& Technology Co., Ltd., Beijing, China) or/and 4-PBA (Sigma-Aldrich; Merck KGaA, Darmstadt, Germany) for 24 or $48 \mathrm{~h}$. TM and 4-PBA were dissolved in dimethyl sulfoxide as a stock solution.

Western immunoblotting. Proteins were extracted from the CRC cells (SW620, HCT116, HT29, LS174T, SW480, LOVO and DLD1) in each group. The cell lysates were removed to detect protein expression using radioimmunoprecipitation assay lysis buffer containing protease inhibitor (Beyotime Institute of Biotechnology, Shanghai, China) at $4^{\circ} \mathrm{C}$ for $30 \mathrm{~min}$. Each group of protein samples was quantified using a Bincinchoninic Acid Protein assay kit (Beyotime Institute of Biotechnology). Cell lysates $(25 \mu \mathrm{g})$ were separated on $10 \%$ SDS-PAGE and then transferred to polyvinylidene fluoride (PVDF) membranes. The membranes were blocked with 5\% skimmed milk in PBS containing 0.1\% Tween-20
(PBS-Tween-20) for $1 \mathrm{~h}$ at room temperature and then incubated with specific primary antibodies at $4{ }^{\circ} \mathrm{C}$ overnight. The rabbit monoclonal antibodies used were heat shock protein family $\mathrm{A}$ (Hsp70) member 5 (GRP78; 1:500; cat. no. 11578-1-AP; ProteinTech Group, Inc., Chicago, IL, USA), heat shock protein $90 \beta$ family member 1 (GRP94; 1:500; cat. no. 0811; Novus Biologicals, LLC, Littleton, CO, USA), ERp29 (1:500; cat. no. GTX102225; GeneTex, Inc., Irvine, CA, USA), CUL5 (1:500; cat. no. BS755; Biogot Technology Co., Ltd., Nanjing, China), snail family transcriptional repressor 1 (SNAIL; 1:500; cat. no. 3879S; Cell Signaling Technology, Inc., Danvers, MA, USA), vimentin (1:500; cat. no. 3932S; Cell Signaling Technology, Inc.), E-cadherin (1:500; cat. no. 8834S; Cell Signaling Technology, Inc.), $\beta$-catenin (1:500; cat. no. 9562S; Cell Signaling Technology, Inc.), replication protein A2 (RPA2; 1:500; cat. no. 52448S; Cell Signaling Technology, Inc.), signal sequence receptor subunit 4 (SSR4; 1:500; cat. no. ab180262; Abcam, Cambridge, MA, USA) and tubulin folding cofactor A (TBCA; 1:500; cat. no. 12304-1-AP; ProteinTech Group, Inc.). Next, the membranes were washed with PBS-Tween-20 five times and incubated with anti-mouse or -rabbit secondary antibodies (1:5,000; cat. nos. ZB-2305 or ZB-2306; Zhongshan Golden Bridge Biotechnology, Beijing, China) at room temperature for $1 \mathrm{~h}$. Protein bands were visualized with an enhanced chemiluminescence western blotting detection system (Thermo Fisher Scientific, Inc.) and analyzed by the Tanon 5200 image acquisition system (Tanon Science and Technology Co., Ltd., Shanghai, China).

Reverse transcription-quantitative polymerase chain reaction $(R T-q P C R)$ analysis. First, total RNA was extracted from CRC cells (SW620 and HCT116) using a TRIzol Reagent kit (Invitrogen; Thermo Fisher Scientific, Inc.) according to the manufacturer's protocol, and then cDNA was synthesized using the Reverse Transcription kit (Takara Biotechnology, Co., Ltd., Dalian, China) according to the manufacturer's protocol. PCR was performed using Ex Taq ${ }^{\mathrm{TM}}$ DNA Polymerase (Takara Bio, Inc., Otsu, Japan) and an ABI PRISM 7500 Sequence Detection System (Applied Biosystems; Thermo Fisher Scientific, Inc.). The reactions were performed as follows: Predegeneration at $95^{\circ} \mathrm{C}$ for $30 \mathrm{sec}$, and PCR for 40 cycles at $95^{\circ} \mathrm{C}$ for $5 \mathrm{sec}$ and $60^{\circ} \mathrm{C}$ for $34 \mathrm{sec}$. The relative level of gene expression was normalized to GAPDH and calculated using $2^{-\Delta \Delta \mathrm{Cq}}[\Delta \mathrm{Cq}=\mathrm{Cq}$ (ERp29 or other genes)-Cq (GAPDH)] (23). Primers used for the RT-qPCR analysis of ERp29, GRP78, GRP94 and GAPDH were as follows: ERp29 forward, 5'-AAAGCAAGT TCGTCTTGGTGA-3' and reverse, 5'-CGCCATAGTCTG AGATCCCCA-3'; GRP78 forward, 5'-CATCACGCCGTCCTA TGTCG-3' and reverse, 5'-CGTCAAAGACCGTGTTCTCG-3'; GRP94 forward, 5'-GCTGACGATGAAGTTGATGTGG-3' and reverse, 5'-CATCCGTCCTTGATCCTTCTCTA-3'; GAPDH forward, 5'-GGAGCGAGATCCCTCCAAAAT-3' and reverse, 5'-GGCTGTTGTCATACTTCTCATGG-3'. Each sample was tested in triplicate.

Immunofluorescence assays. At room temperature, the cells (SW620 and HCT116) were fixed with 4\% paraformaldehyde for $30 \mathrm{~min}$, then 1\% Triton X-100 (cat. no. 0694; Amresco, LLC, Solon, OH, USA) was added for $10 \mathrm{~min}$ to puncture the cell membrane. Bovine serum albumin (1\%) was used for 
non-specific binding. Next, the cells were incubated with the antibodies for ERp29 (1:100; sc-49658; Santa Cruz Biotechnology, Inc., Santa Cruz, CA, USA), GRP78 (1:50; cat. no. 11578-1-AP; ProteinTech Group, Inc.) and CUL5 (1:50; cat. no. BS755; Biogot Technology Co., Ltd.) at $4^{\circ} \mathrm{C}$ overnight, and then at room temperature, stained with an anti-rabbit or mouse $\operatorname{IgG}(\mathrm{H}+\mathrm{L})$ secondary antibody for $1 \mathrm{~h}$ (1:100, cat. no. ZF-0511; and 1:100, cat. no. ZF-0513; Zhongshan Golden Bridge Biotechnology), followed by 4',6-diamidino-2-phenylindole staining $(5 \mu \mathrm{g} / \mathrm{ml}$; Beyotime Biotechnology) for $10 \mathrm{~min}$ at room temperature. Finally, the cells were observed via a confocal fluorescence microscope (FV1000; Olympus Corporation, Tokyo, Japan) at x200 magnification.

Cell Counting Kit 8 (CCK8) assays. A total of $10^{3}$ cells (SW620 and HCT116) were seeded into each well of a 96-well plate, and then CCK8 reagent (cat. no. CK04; Dojindo Molecular Technologies, Inc., Kumamoto, Japan) at a ratio of CCK8:serum-free RPMI-1640 medium of 1:9, was added to measure cell proliferation induction at $0,24,48,72,96$ and $120 \mathrm{~h}$. Subsequent to adding the CCK8 reagent, the cells were incubated at $37^{\circ} \mathrm{C}$ for $2 \mathrm{~h}$. Optical density was obtained from cell growth curve analysis.

Transwell assays. The lower chambers (cat. no. 353097; BD Biosciences, San Diego, CA, USA) were supplemented with $500 \mu 110 \%$ fetal bovine serum in RPMI-1640 medium as a chemotactic factor. Next, a total of $5 \times 10^{4}$ cells (SW620 or HCT116) were mixed with serum-free RPMI-1640 medium in the upper chambers for 24 or $48 \mathrm{~h}$ at $37^{\circ} \mathrm{C}$ and $5 \% \mathrm{CO}_{2}$. Cells in the upper chamber were removed with a cotton swab. Next, at room temperature, the chambers were fixed with $4 \%$ paraformaldehyde for $30 \mathrm{~min}$ and Giemsa staining $(\mathrm{A}: \mathrm{B}=1: 2)$ was applied for $20 \mathrm{~min}$. Finally, the cells in the lower chamber were observed and counted under a light microscope at x200 magnification.

Animal models. The study was approved by the Southern Medical University Animal Care and Use Committee (Southern Medical University, Guangzhou, China). For the animal studies, 4-week-old nude mice (15-20 g; male), which were obtained from the Experimental Animal Center of Southern Medical University and fed in specific pathogen-free conditions (housed at $20-25^{\circ} \mathrm{C}$ in $55-60 \%$ relative humidity, using a $12 \mathrm{~h}$ light/12 h dark cycle and provided with commercial food and water ad libitum throughout) were randomly distributed into 4 groups, with 5 mice in each group. A total of $5 \times 10^{6}$ SW620 cells were subcutaneously injected for the assessment of cancer cell growth. In addition, $5 \times 10^{6}$ cells were injected into the spleens of nude mice to simulate the experimental metastasis of the liver. After 3 weeks, the subcutaneous masses of tumors or liver metastases were detected using in vivo imaging (FX Pro; Bruker Scientific Technology Co., Ltd., Beijing, China). Next, the nude mice were sacrificed by cervical dislocation and the subcutaneous masses of tumors or liver metastases were removed from the animals for histopathological analysis.

Hematoxylin and eosin staining $(H \& E)$. Animal tumor tissues were fixed in $10 \%$ neutral buffered formalin for $24 \mathrm{~h}$ and embedded in paraffin; tumor tissues were cut into 3- $\mu \mathrm{m}$ sections. At room temperature, the tissues sections were deparaffinized twice in $100 \%$ dimethylbenzene for $25 \mathrm{~min}$ and rehydrated in a descending series of ethanol concentrations (100, 95, 80, 70 and $50 \%$ ). Thereafter, all tissues sections were stained with hematoxylin (cat. no. G1120; Solarbio) at room temperature for $5 \mathrm{~min}$ and washed under running tap water for $5 \mathrm{~min}, 1 \%$ hydrochloric acid alcohol for 10-15 sec and running tap water for $20 \mathrm{~min}$. Next, all tissues slices were stained with eosin for $2 \mathrm{~min}$ at room temperature (cat. no. G1120; Solarbio). Dehydration in a descending series of ethanol concentrations (70, 80, 95 and $100 \%$ ) and vitrification by $100 \%$ dimethylbenzene for $5 \mathrm{~min}$ was then performed. Finally, the tissues were observed under a light microscope (magnification, x200 or 400).

Co-immunoprecipitation. Cell (SW620 and HCT116) extracts were collected as described in the western immunoblotting section. Next, the cell extracts were incubated with protein $\mathrm{A}+\mathrm{G}$ agarose (Santa Cruz blotechnology, Inc.) for $1 \mathrm{~h}$ at $4^{\circ} \mathrm{C}$. The protein $\mathrm{A}+\mathrm{G}$ agarose was removed and the antibodies for ERp29 (1:20; cat. no. sc-49658; Santa Cruz Biotechnology, Inc.) or CUL5 (1:25; cat. no. BS755; Biogot Technology Co., Ltd.) or control IgG (1-2/100-500 $\mu \mathrm{g}$ of total protein; Santa Cruz Biotechnology, Inc.) were added for incubation overnight at $4^{\circ} \mathrm{C}$. Once protein $\mathrm{A}+\mathrm{G}$ agarose was added for $8 \mathrm{~h}$ at $4^{\circ} \mathrm{C}$, the beads were washed with cold PBS and then centrifuged at $670.8 \mathrm{x} \mathrm{g}$ for $10 \mathrm{~min}$ at $4^{\circ} \mathrm{C}$. The supernatant was collected. The subsequent processing was performed in accordance with western blotting as described above.

Gene transfection carriers. Overexpression plasmid and lentivirus vectors of ERp29 were constructed by and purchased from Shanghai GenePharma Co., Ltd according to the manufacturer's protocols (Shanghai, China). The lentivirus vectors silencing ERp29 were purchased from Shanghai GeneChem Co., Ltd., according to the manufacturer's protocols (Shanghai, China). The effective silencing fragment for ERp29 was CCCTGGATACGGTCACTTT. SW620 and HCT116 cells were seeded in 6-well plates at a density of $5 \times 10^{6}$ cells/well. After 24 h, ERp29-overexpressing or control cell lines were constructed by infecting cells with lentivirus ERp29, shERp29 and control vector at $37^{\circ} \mathrm{C}$ for $48 \mathrm{~h}$. The cells were then subjected to immunoblot analysis. The siRNA specific for CUL5 (UUCCGGUAUCAAGUCCUCCTT) or control siRNA (UUCUCCGAACGUGUCACGUTT) were purchased from Guangzhou Dahong Biosciences (Guangzhou, China), according to the manufacturer's protocols. SW620 and HCT116 cells were seeded in 6-well plates and control siRNA or CUL5 siRNA was transfected using Lipofectamine ${ }^{\circledR} 2000$ according to the manufacturer's protocols (Thermo Fisher Scientific, Inc.). After $48 \mathrm{~h}$, the cells were collected and analyzed by immunoblotting.

Tumor samples and immunohistochemistry. The 457 tumor samples of CRC were supplied by the Nanfang Hospital of Southern Medical University (Guangzhou, China). The patients included 244 men and 213 women (median age, 60 years; range, 19-86 years). The patients and/or their relatives were written informed consent to the use of their clinical materials for research purposes and ethical approval was 
obtained from the Ethics Committee of Southern Medical University. At room temperature, tumor and paracarcinoma tissues were fixed in $10 \%$ neutral buffered formalin for $24 \mathrm{~h}$ and cut into $3-\mu \mathrm{m}$ thick sections. Tissues were deparaffinized and rehydrated following conventional processes. The tissues were then blocked with goat serum for $1 \mathrm{~h}$ at room temperature. Next, the expression of ERp29 and CUL5 was detected and immunostained using primary antibodies (ERp29, 1:300, cat. no. ab11420, Abcam; CUL5, 1:250, cat. no. BS755, Biogot Technology Co., Ltd.) at $4^{\circ} \mathrm{C}$ overnight. At room temperature, the tissues were incubated for $1 \mathrm{~h}$ with anti-mouse or anti-rabbit HRP-labeled IgG polymer and then DAB $(1: 50)$ for 1 min (EnVision Detection System; cat. no. K500711; Dako; Agilent Technologies, Inc., Santa Clara, CA, USA). The immunochemistry results for ERp29 and American Joint Committee on Cancer (AJCC) stages were evaluated as previously described $(9,24)$. The staining intensity of CUL5 was scored as weak (0-25\%) or strong (26-100\%) based on the percentage of the positive staining areas of the carcinoma-involved area.

Statistical analysis. The data are presented as the mean \pm standard deviation. Independent samples t-test or one-way analysis of variance with Tukey's post hoc test was adopted for the comparison of independent experimental groups. The association between ERp29 expression and the clinicopathological features was obtained using a $\chi^{2}$ test, and the expression of CUL5 using a Fisher's exact test. The Kaplan-Meier method was used to obtain survival curves. All statistics were analyzed by SPSS software (version 13.0; SPSS, Inc., Chicago, IL, USA) and GraphPad Prism (version 6.02; GraphPad Software Inc., La Jolla, CA, USA). $\mathrm{P} \leq 0.05$ was considered to indicate a statistically significant difference.

\section{Results}

ERp29 is involved in ERS of CRC. The present study initially detected the endogenous expression of ERp29 in seven CRC cell lines. The cell lines that produced a lower expression, SW620 and HCT116, were selected for subsequent experiments (Fig. 1A). Next, an ERS model of TM incubation was constructed to demonstrate time-concentration effects. Once the SW620 and HCT116 cells were cultured in media supplemented with $20 \mu \mathrm{g} / \mathrm{ml} \mathrm{TM}$ for 24 and $48 \mathrm{~h}$, respectively, the post-treated cells produced significantly increased expression of molecules associated with ERS response, including GRP94 and GRP78, which are considered to be representative proteins of ERS (25-27) and localized in the ER, when compared with untreated cells $(\mathrm{P}<0.05$; data not shown). To investigate whether ERp29 expression reacted to TM-induced-ERS, it was revealed that ERp29 expression was significantly upregulated under TM stimulation when compared with untreated cells $(\mathrm{P}<0.05$; data not shown). Therefore, $20 \mu \mathrm{g} / \mathrm{ml} \mathrm{TM}$ was incubated with SW620 cells for $24 \mathrm{~h}$ and HCT116 cells for $48 \mathrm{~h}$, respectively, in order to induce the state of ERS. 4-PBA is able to neutralize the effect of ERS as described by Choi et al (28). Different concentrations $(0,2.5,5$ and $10 \mathrm{mmol} / \mathrm{l})$ of 4 -PBA were selected to neutralize the TM induction effects. Concentration assessment revealed that $10 \mathrm{mmol} / \mathrm{l}$ of 4-PBA was cytotoxic to the cultured cells, whereas $5 \mathrm{mmol} / \mathrm{l}$ of 4 -PBA was optimal to treat the cells (data not shown). The results revealed that
GRP78 and GRP94 expression was substantially decreased in the SW620 cells at $24 \mathrm{~h}$ and HCT116 cells at $48 \mathrm{~h}$, respectively when compare with TM-treated cells (Fig. 1B). Simultaneously, ERp29 expression was also substantially downregulated when compared with TM-treated cells (Fig. 1B). Therefore, $5 \mathrm{mmol} / \mathrm{l}$ 4-PBA was determined to counteract the state of TM-induced ERS. The quantitative PCR of ERp29, GRP78 and GRP94 produced mRNA expression levels consistent with the protein levels, with significantly increased expression levels in the TM-treated groups compared with the control and significantly decreased expression levels in the TM+4-PBA group compared with the TM-treated group ( $\mathrm{P}<0.01$; Fig. 1C). The immunofluorescence assay revealed that ERp29 and GRP78 co-localized in SW620 and HCT116 cells; this indicated that ERp29 was located in the ER and may be associated with ERS (Fig. 1D). These data revealed that cancer cells during ERS produce an enhanced expression of ERp29.

Next, ERp29 in association with ERS should be requisite to investigate. Therefore, the present study established stably ERp29-overexpressing (hiERp29) and ERp29-silenced [short hairpin RNA (sh)ERp29] cell lines of SW620 and HCT116, and confirmed the transfection efficiency (Fig. 1E). It was revealed that TM-conditioned media was able to induce ERS in hiERp29 and shERp29 cell lines (Fig. 1F). During ERS, ERp29 was highly upregulated in hiERp29 cells and downregulated in shERp29 cells. These data demonstrate that ERp29 expression in cancer cells is positively associated with ERS state.

ERp29 reduces the ERS-induced inhibition of CRC cell growth. A CCK-8 cell proliferation assay revealed that the proliferation of SW620 and HCT116 cells was significantly suppressed by $\mathrm{TM}$, and partly recovered by supplementation with 4-PBA compared with the control cells $(\mathrm{P}<0.05$; Fig. $2 \mathrm{~A})$. In contrast, hiERp29 cells during ERS exhibited a significantly enhanced proliferative rate compared with the control cells $(\mathrm{P}<0.05$; Fig. 2B), whereas the proliferation of shERp29 cells decreased significantly ( $\mathrm{P}<0.05 ;$ Fig. $2 \mathrm{~B})$. Therefore, ERp29 was a positive factor involved in cancer cell proliferation during ERS.

Animal models with subcutaneous tumors revealed that the mean volume of the tumor was $1.2698 \pm 0.0732 \mathrm{~cm}^{3}(\mathrm{n}=5)$ in the vector group and $0.3428 \pm 0.0862 \mathrm{~cm}^{3}(\mathrm{n}=5)$ in the TM-treated CRC cell group; with a significant difference identified between these groups ( $\mathrm{P}<0.01$; Fig. $2 \mathrm{C}$ and $\mathrm{D})$. For TM-treated cells, the mean volume of the tumors in the hiERp29 group $\left(0.6816 \pm 0.1129 \mathrm{~cm}^{3}, \mathrm{n}=5\right)$ were significantly larger compared with that of the shERp29 group $\left(0.1692 \pm 0.0365 \mathrm{~cm}^{3}, \mathrm{n}=5\right)$ $(\mathrm{P}<0.01$; Fig. $2 \mathrm{C}$ and $\mathrm{D})$. Animal in vivo images labeled with GFP revealed that the tumor masses of the hiERp29 group were larger and more intensively fluorescent compared with those in the shERp29 group (Fig. 2F). Microscopic observation did not reveal any histopathological differences in the hematoxylin and eosin staining of these tumor tissues (Fig. 2E). Thus, animal models revealed that ERp29 promoted CRC cell growth during ERS.

ERS inhibits the migration and metastasis of CRC cells, but ERp29 offsets these effects. A Transwell cell migration assay revealed that the number of invaded cells was significantly decreased following treatment with $\mathrm{TM}$, and partly retrieved subsequent to being supplemented with 4 -PBA $(\mathrm{P}<0.01$; 
A
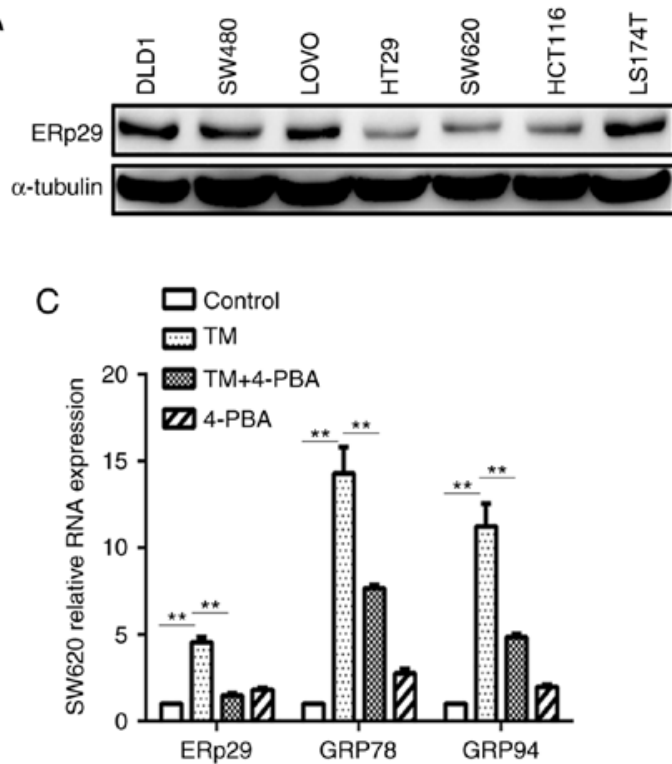

D

B
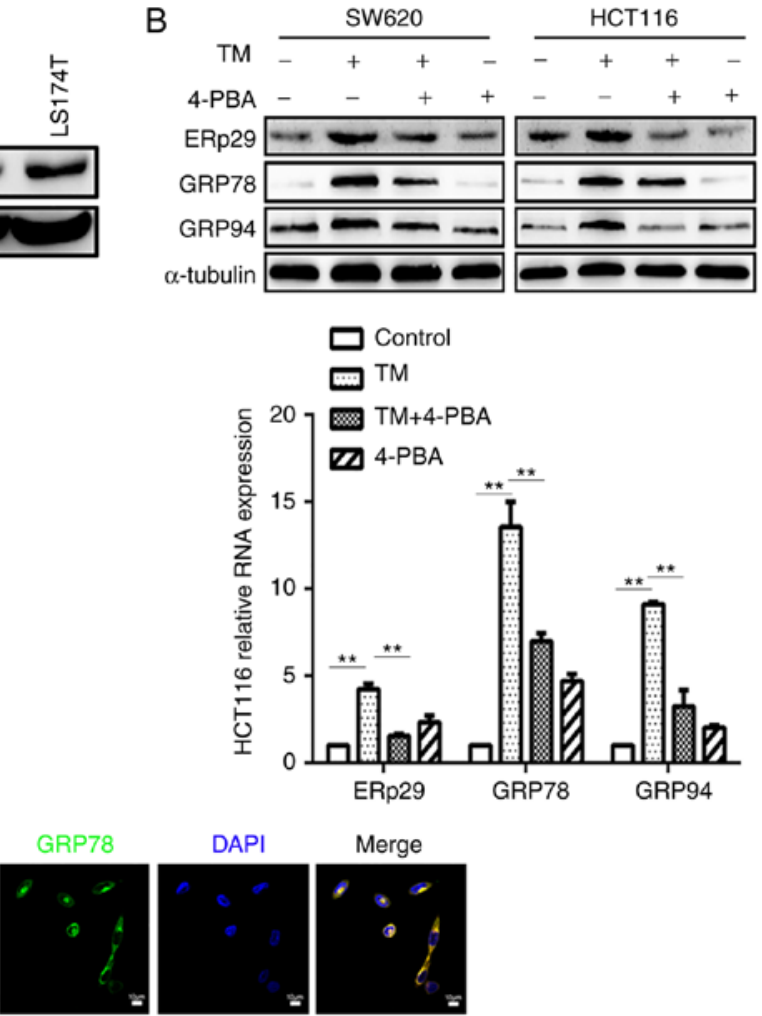

Merge
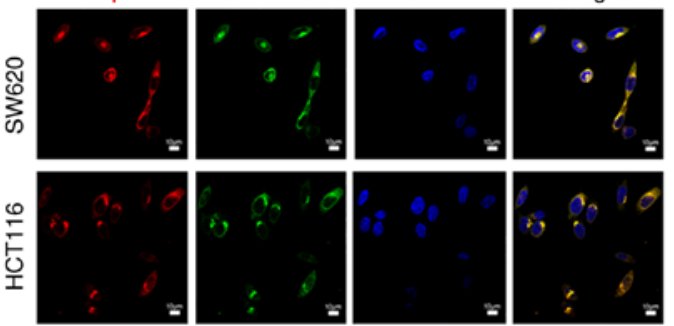

E
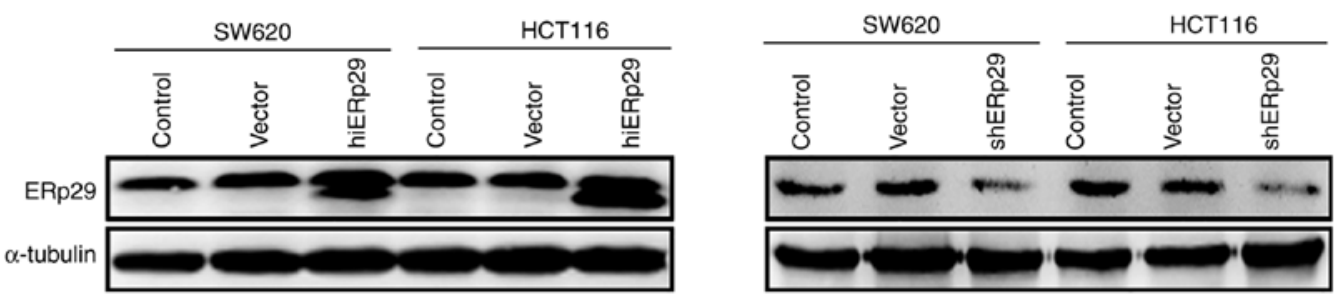

$\mathrm{F}$

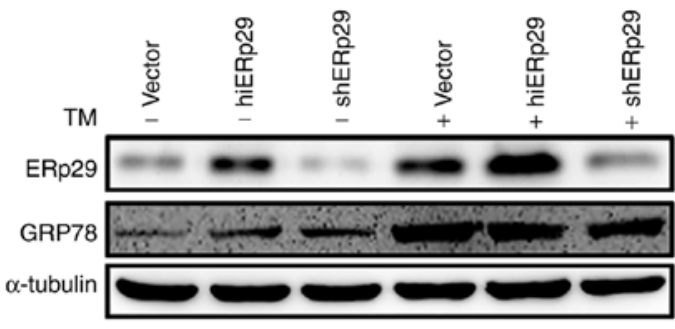

SW620

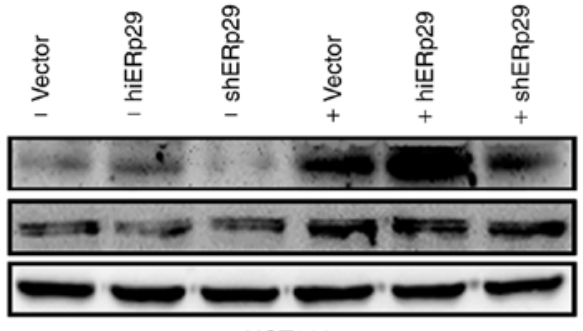

HCT116

Figure 1. ERp29 participated in the endoplasmic reticulum stress of CRC cells. (A) ERp29 was expressed in seven CRC cell lines. The expression of ERp29, GRP78 and GRP94 in SW620 and HCT116 cells subsequent to incubation with $20 \mu \mathrm{g} / \mathrm{ml} \mathrm{TM}$ and $5 \mathrm{mmol} / 1$ 4-PBA for 24 or $48 \mathrm{~h}$, respectively, were measured by (B) western blotting and (C) reverse transcription-quantitative polymerase chain reaction. ${ }^{* *} \mathrm{P}<0.01$ with comparisons shown by lines. (D) Immunofluorescent images of ERp29 co-locating with GRP78 in CRC cells. (E) Constructed overexpressing ERp29 (hiERp29) and silencing ERp29 (shERp29) stable cell lines. (F) Expression of ERp29 and GRP78 in hiERp29 and shERp29 cells subsequent to TM stimulation. ERp29, endoplasmic reticulum protein 29; CRC, colorectal cancer; GRP78, heat shock protein family A (Hsp70) member 5; GRP94, heat shock protein $90 \beta$ family member 1; TM, tunicamycin; 4-PBA, 4-phenylbutyric acid; hi-, high; sh-, short hairpin RNA.

Fig. 3A and B). Nevertheless, in the TM-treated groups, the invaded cells were significantly increased in hiERp29 cells, and were significantly decreased in shERp29 cells compared with the control $(\mathrm{P}<0.05$; Fig. $3 \mathrm{C}$ and $\mathrm{D})$. The results indicated that during ERS, ERp29 enhanced the migration capacity of CRC cells.
An experimental metastatic assay revealed that TM significantly inhibited the liver metastases of mice $(n=5, P<0.05$; Fig. $3 \mathrm{E}$ and F). In vivo images revealed that hiERp29 cells produced liver metastases, but shERp29 cells did not following TM treatment $(\mathrm{n}=5$; Fig. 3G). Furthermore, during ERS, macroscopic observations revealed that the metastatic nodules were more prevalent 
A

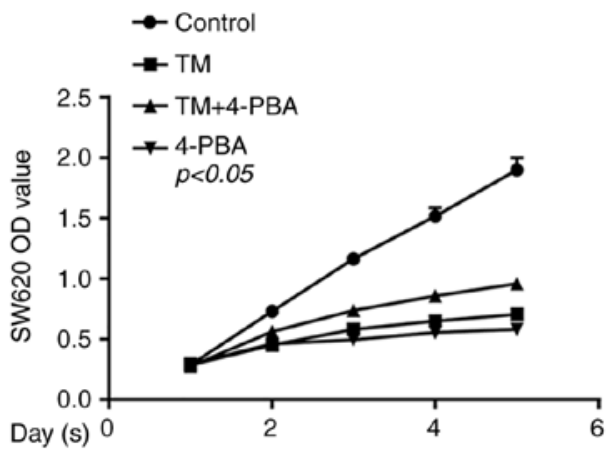

B

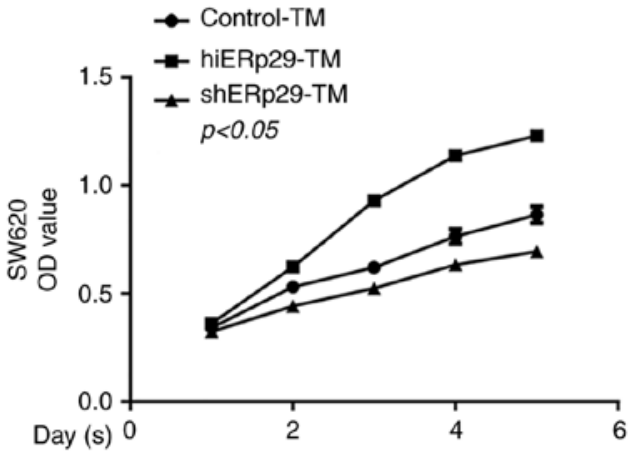

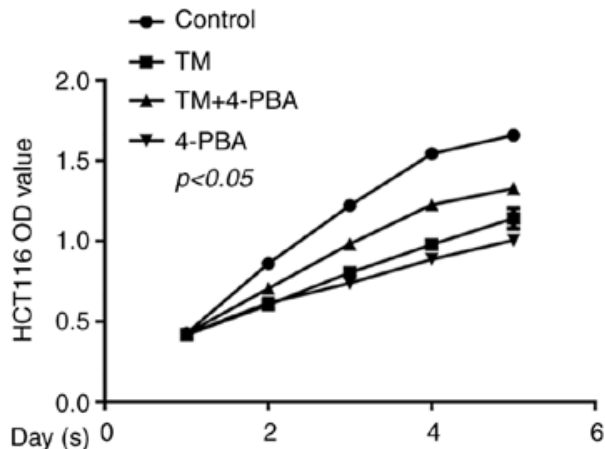

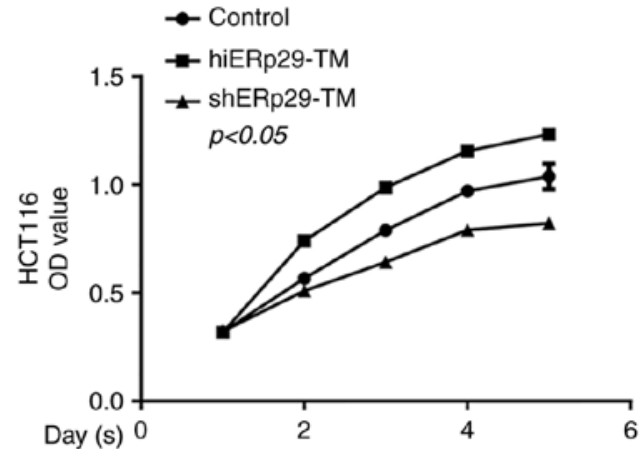

Day (s) 0
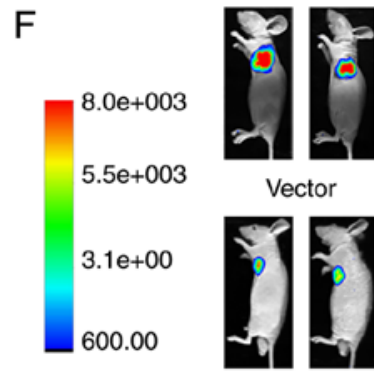

Vector

Vector

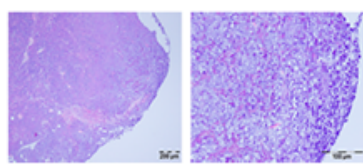

Vector-TM

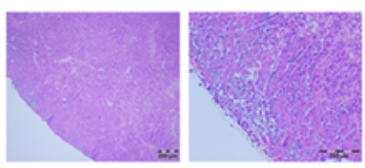

hiERp29-TM

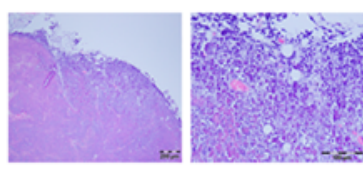

shERp29-TM

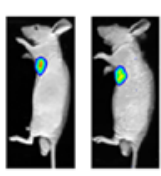

Vector-TM

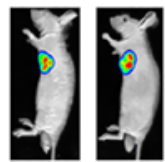

hiERp29-TM

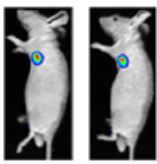

ShERP29-TM

Figure 2. Growth curve and xenotransplantation revealed that ERp29 counteracted the endoplasmic reticulum stress-inducing inhibition of CRC cell proliferation. (A) A Cell Counting Kit-8 proliferation assay revealed that the proliferation of CRC cells was significantly slower in SW620-TM and HCT116-TM cells; correspondingly, the cell growth inhibition receded under supplementation with 4-PBA. TM, $20 \mu \mathrm{g} / \mathrm{ml} ; 4-\mathrm{PBA}, 5 \mathrm{mmol} / 1$. (B) TM-treated cells demonstrated a higher proliferation rate in the hiERp29 group and presented a lower rate in the shERp29 group. Tumor masses of hiERp29 and shERp29 cells with TM stimulation in nude mice as presented in a subcutaneous (C) tumor profile, (D) quantified tumor size, (E) histological images of hematoxylin and eosin staining (scale bar, 200 and $100 \mu \mathrm{m}$ ) and (F) in vivo imaging. Error bars represent the mean \pm standard deviation of experiments in triplicate. ${ }^{*} \mathrm{P}<0.05$ and ${ }^{* *} \mathrm{P}<0.01$ with comparisons shown by lines. ERp29, endoplasmic reticulum protein 29; CRC, colorectal cancer; TM, tunicamycin; 4-PBA, 4-phenylbutyric acid; hi-, high; sh-, short hairpin RNA; OD, optical density.

and larger in the hiERp29 group compared with the shERp29 group ( $\mathrm{n}=5, \mathrm{P}<0.01$; Fig. $3 \mathrm{E}$ and $\mathrm{F})$, although the tumor volume generated in the spleen had little variation amongst all groups $(\mathrm{n}=5$, Fig. 3E). The macroscopic tumor masses were confirmed by histopathological examination, but they did not present any histological differences (Fig. 3E). The animal models suggested that ERp29 may promote metastases during ERS. These results revealed that ERp29 functions as an impeller in CRC aggressiveness when the cells are under the ERS state.

ERp29 coupling with CUL5 protects CRC cells from the ERS-mediated depression of malignancy. Two-dimensional electrophoresis revealed different protein dots between SW620 and hiERp29 SW620 cells, and then they were 

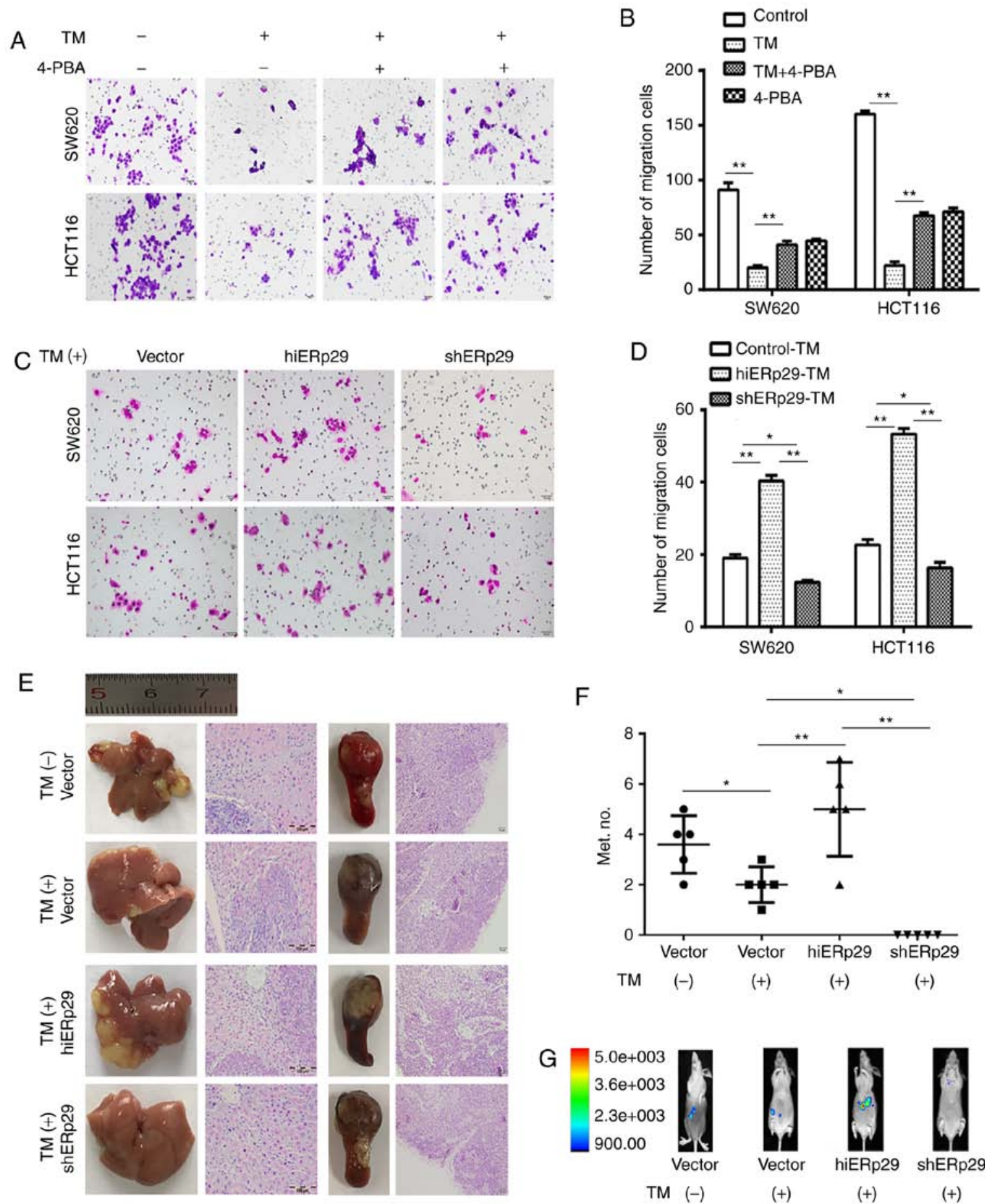

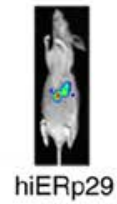

(+)

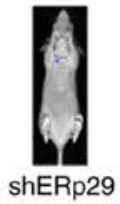

$(+)$

Figure 3. Endoplasmic reticulum stress inhibits the migration and metastasis of CRC cells, but ERp29 offsets these effects. (A) A Transwell invasion assay revealed that the migration rate of cells was reduced in SW620-TM and HCT116-TM cells; correspondingly, the cell migration inhibition receded under supplementation with 4-PBA. TM, $20 \mu \mathrm{g} / \mathrm{ml}$; 4-PBA, $5 \mathrm{mmol} / 1$. Scale bar, $50 \mu \mathrm{m}$. (B) Quantified Transwell invasion assay results. (C) A Transwell invasion assay revealed an increase in cell migration in hiERp29 cells or the decreasing migration of shERp29 cells in comparison with the control when the cells were stimulated with TM. Scale bar, $50 \mu \mathrm{m}$. (D) Quantified Transwell invasion assay results. (E) Experimental metastases of nude mice livers and spleen tumors of inoculated CRC cells with histopathological images. Scale bar, 100 and $50 \mu \mathrm{m}$. (F) In vivo imaging of mice peritoneal cavities and (G) quantified number of liver metastases. Error bars represent the mean \pm standard deviation. ${ }^{*} \mathrm{P}<0.05$ and ${ }^{* *} \mathrm{P}<0.01$ with comparisons shown by lines. CRC, colorectal cancer; ERp29, endoplasmic reticulum protein 29; TM, tunicamycin; 4-PBA, 4-phenylbutyric acid; hi-, high; sh-, short hairpin RNA.

confirmed by matrix-assisted laser desorption ionization time-of-flight mass spectrometry (data not shown) $(29,30)$. The candidate proteins were CUL5, SSR4, RPA2 and TBCA, and their expressions were verified using RT-qPCR and western blotting (data not shown). CUL5, as a scaffolding protein in E3 ligase complexes, is functionally involved in numerous cellular activities including cell growth, cell cycle, apoptosis and cancer cell invasion (31-35). The present study therefore investigated whether CUL5 was able to confer the synergistic effect of ERp29 to regulate the biological behavior of tumor cells. To investigate this, immunofluorescence and co-immunoprecipitation tests revealed that CUL5 


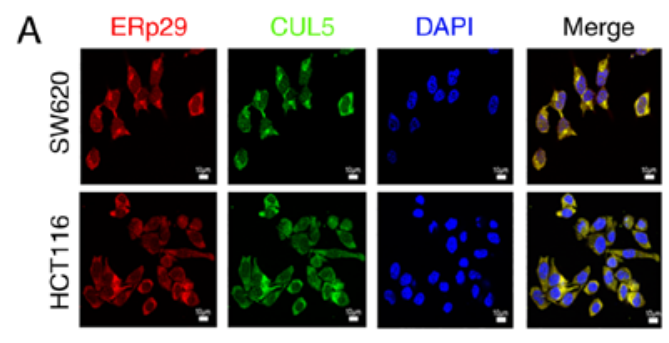

B
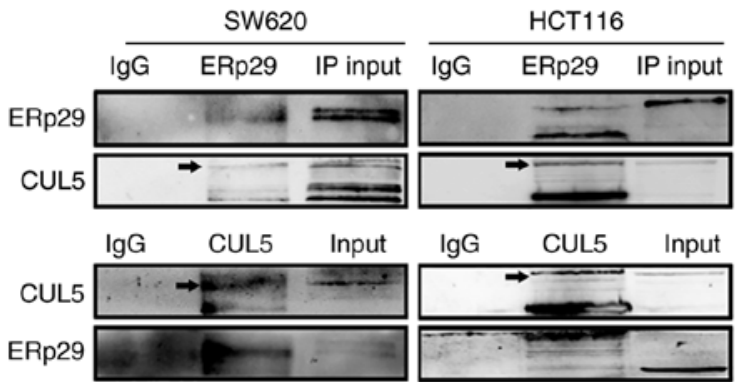

C

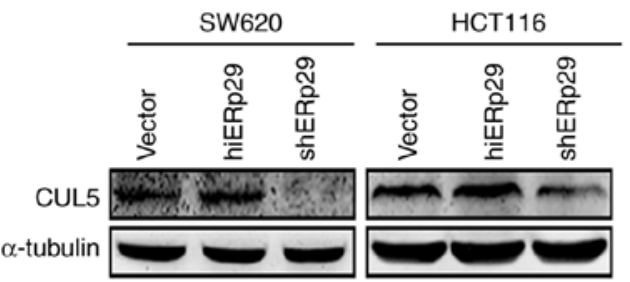

D
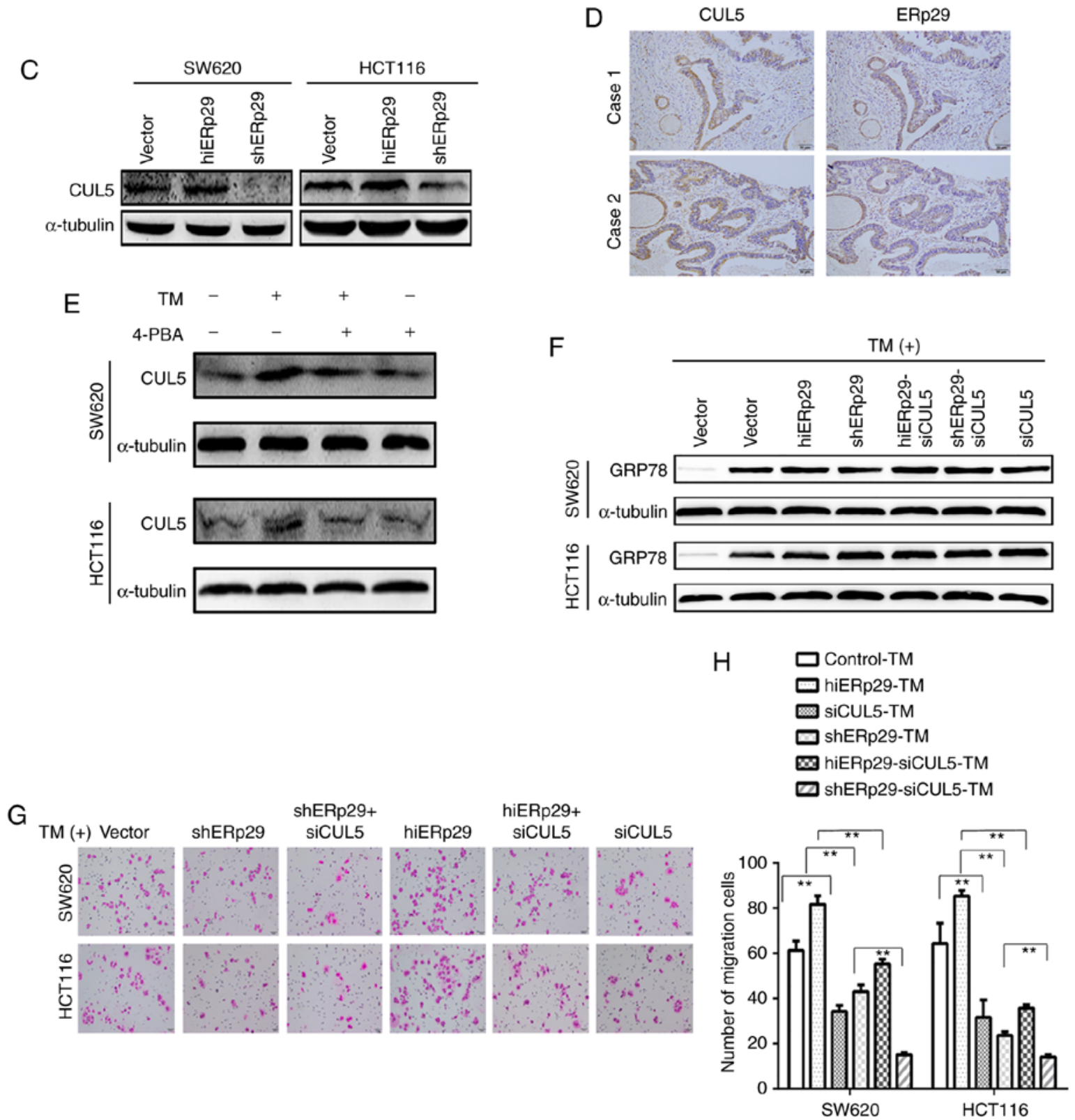

Figure 4. ERp29 coupling with CUL5 protects CRC cells from the ERS-mediated suppression of malignancies. (A) Immunofluorescence images of ERp29 co-locating with CUL5 in CRC cells. (B) Co-immunoprecipitation revealed that ERp29 interacted with CUL5 in CRC cells. (C) Expression of CUL5 in hiERp29 and shERp29 cell lines. (D) Expression of CUL5 and ERp29 in series of tumor sample sections from patients with CRC; scale bar, $50 \mu \mathrm{m}$. (E) Expression of CUL5 was upregulated with TM stimulation. (F) hiERp29-siCUL5 and shERp29-siCUL5 cells in ERS. (G) When the hiERp29 cells or shERp29 cells were affected by the knockdown of CUL5 and treated with TM, the migration rates were substantially reduced. Scale bar, $50 \mu \mathrm{m}$. (H) Quantified migration rates. Error bars represent the mean \pm standard deviation of experiments in triplicate. ${ }^{* *} \mathrm{P}<0.01$ with comparisons shown by lines. CRC, colorectal cancer; ERp29, endoplasmic reticulum protein 29; CUL5, cullin 5; TM, tunicamycin; hi-, high; sh-, short hairpin RNA; si-, small interfering RNA; ERS, endoplasmic reticulum stress; 4-PBA, 4-phenylbutyric acid; IgG, immunoglobulin G.

co-localized and interacted with ERp29 in SW620 and HCT116 cells (Fig. 4A and B).
Subsequently, the expression of CUL5 was revealed to be consistent with that of ERp29 in hiERp29 and shERp29 CRC 
cells (Fig. 4C). Immunohistochemistry examination of serial sections revealed that CUL5 and ERp29 were co-expressed intensively in 30 cases of human CRC tissues $\left(\chi^{2}=6.239\right.$, $\mathrm{P}<0.05$; Fig. 4D). Consistent with the expression of ERp29, CUL5 expression was substantially increased subsequent to TM treatment and decreased when supplemented with 4-PBA in cultured cells (Fig. 4E). These data indicated that ERp29 was coupled with CUL5 to create a synergistic effect in the ERS of CRC cells.

When the knockdown of CUL5 occurred, hiERp29-small interfering RNA (si)CUL5, shERp29-siCUL5 and siCUL5 cell lines were obtained (data not shown). Accordingly, GRP78 was highly expressed in these cells following TM stimulation, meaning that ERS may be triggered in these cells (Fig. 4F). The Transwell assay results revealed that the invaded cells were significantly fewer in the hiERp29-siCUL5 group compared with the hiERp29 group compared with cells treated with TM $(\mathrm{P}<0.01)$. Similarly, the invaded cells were fewer in the shERp29-siCUL5 group compared with in the shERp29 group $(\mathrm{P}<0.01$; Fig. 4G and $\mathrm{H})$. These results revealed that ERp29 should rely on CUL5 to restore invasiveness in CRC cells during ERS.

ERp29 relies on CUL5 to promote EMT. EMT provides a novel challenge and opportunity for the invasive and migratory behaviors of cancer cells. In order to further understanding of how ERp29 promotes cell migration and invasion, the expression of EMT-associated proteins were measured. When SW620 and HCT116 cells were treated with TM, the expression of E-cadherin, associated with the epithelial phenotype, was increased, and the expression of mesenchymal phenotype proteins vimentin, SNAIL and $\beta$-catenin, were decreased in comparison with untreated CRC cells (Fig. 5A). When the cells were treated with TM and supplemented with 4-PBA, the epithelial and mesenchymal proteins were restored to the same expression pattern as that of the blank control (Fig. 5A).

In the TM-treated cells, the expression E-cadherin was decreased and vimentin, SNAIL and $\beta$-catenin were increased in hiERp29 cells in comparison with shERp29 cells or control cells (Fig. 5B and C). Furthermore, the expression of E-cadherin was increased and vimentin, SNAIL and $\beta$-catenin were decreased in hiERp29-siCUL5 cells compared with hiERp29 cells, and the analogous bands of the EMT proteins were presented in shERp29-siCUL5 cells compared with shERp29 cells (Fig. 5B and C). Therefore, when CRC cells were in the state of ERS, the high expression of ERp29 required the cooperation of CUL5 in order to promote EMT.

High expression of ERp29 was associated with a poor prognosis of patients with CRC. Immunohistochemical examination revealed ERp29 localizing in the cytoplasm of CRC cells of clinical samples, but demonstrated intensive variation between individuals (Fig. 6A). To further analyze the association of ERp29 with clinical features, the data revealed that ERp29 expression levels had no significant association with sex, age, location and tumor size (Table I). However, it was revealed that the high expression of ERp29 was associated with lymph node metastasis, AJCC stages,

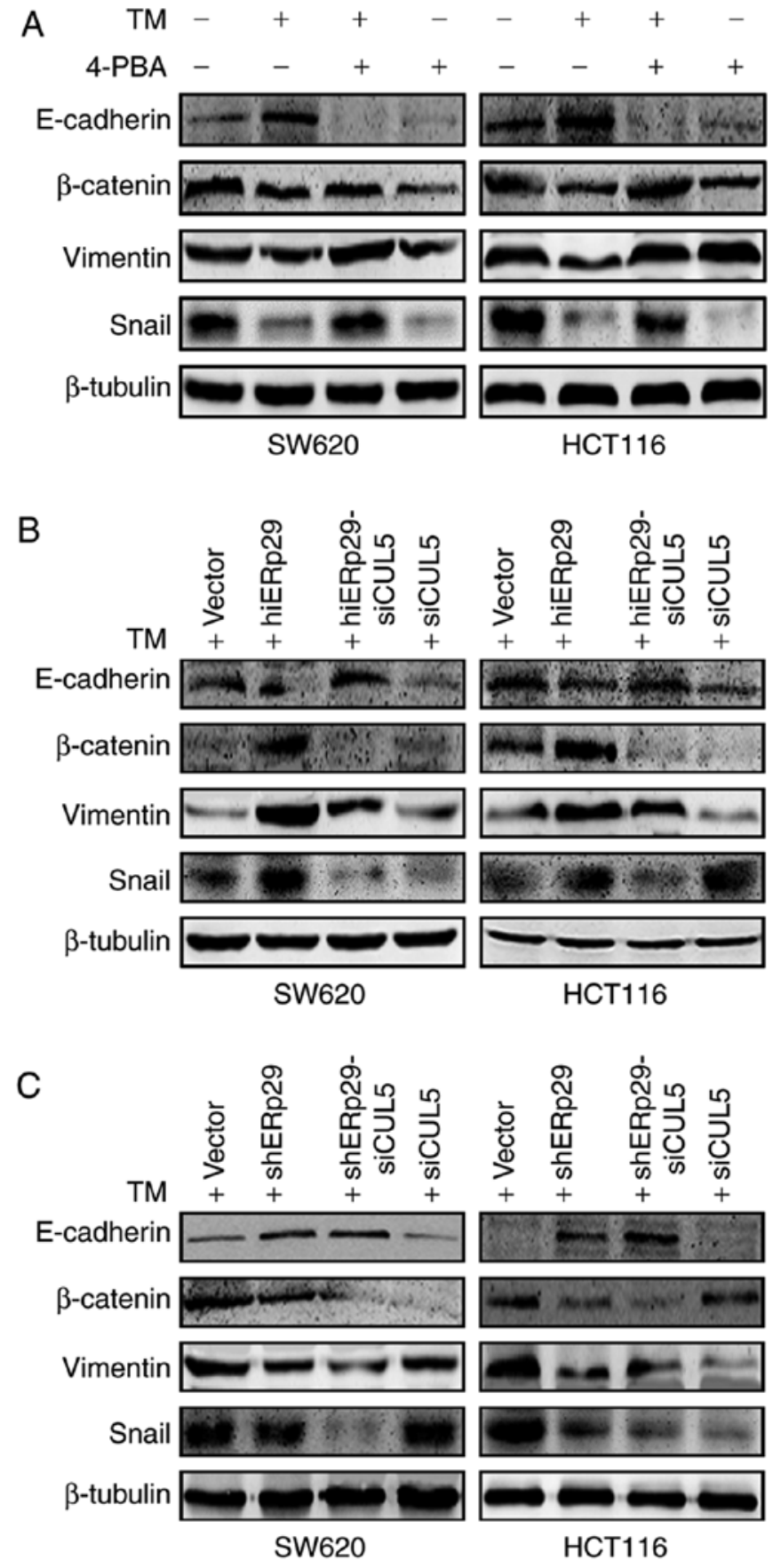

Figure 5. ERp29 promotes EMT during ERS depending on the cooperation of CUL5. Western blotting revealed the expression of EMT-associated proteins in (A) colorectal cancer cells under TM stimulation and/or supplemented with 4-PBA, (B) hiERp29 and hiERp29-siCUL5 cells during TM stimulation, and (C) shERp29 and shERp29-siCUL5 cells during TM stimulation. ERp29, endoplasmic reticulum protein 29; EMT, epithelial-mesenchymal transition; CUL5, cullin 5; TM, tunicamycin; hi-, high; sh-, short hairpin RNA; si-, small interfering RNA; 4-PBA, 4-phenylbutyric acid; Snail, snail family transcriptional repressor 1 .

status and survival time $(\mathrm{P}<0.001$; Table I). Kaplan-Meier survival analysis revealed that the low expression of ERp29 was associated with a prolonged survival time of patients with $\mathrm{CRC}(\mathrm{P}<0.001$; Fig. 6B). Clinicopathological analysis demonstrated that the high expression of ERp29 was associated with aggressive behaviors and an unfavorable prognosis of CRC. 
Table I. Expression of ERp29 associated with clinical characteristics in patients with colorectal cancer $(n=457)$.

\begin{tabular}{|c|c|c|c|c|c|}
\hline \multirow[b]{2}{*}{ Feature } & \multirow[b]{2}{*}{ No. patients (\%) } & \multicolumn{2}{|c|}{ ERp29 immunoreactivity } & \multirow[b]{2}{*}{$\chi^{2}$} & \multirow[b]{2}{*}{ P-value } \\
\hline & & Negative (135) & Positive (322) & & \\
\hline \multicolumn{6}{|l|}{ Age (years) } \\
\hline$\leq 60$ & $221(48.4)$ & $72(53.3)$ & $149(46.3)$ & 1.899 & 0.168 \\
\hline$>60$ & $236(51.6)$ & $63(46.7)$ & $173(53.7)$ & & \\
\hline \multicolumn{6}{|l|}{ Sex } \\
\hline Male & $244(53.4)$ & $63(46.7)$ & $181(56.2)$ & 3.482 & 0.062 \\
\hline Female & $213(46.6)$ & $72(53.3)$ & $141(43.8)$ & & \\
\hline \multicolumn{6}{|l|}{ Location } \\
\hline Colon & $215(47.0)$ & $57(42.2)$ & $158(49.1)$ & 1.790 & 0.181 \\
\hline Rectum & $242(52.0)$ & $78(57.8)$ & $164(50.9)$ & & \\
\hline \multicolumn{6}{|l|}{ AJCC stage } \\
\hline I & $67(14.7)$ & $29(21.4)$ & $38(11.8)$ & 16.947 & $<0.001$ \\
\hline II & $180(39.4)$ & $63(46.7)$ & $117(36.3)$ & & \\
\hline III/IV & $210(45.9)$ & $43(31.9)$ & 167 (51.9) & & \\
\hline \multicolumn{6}{|l|}{ Size $(\mathrm{cm})$} \\
\hline$<3$ & $207(54.7)$ & $63(46.7)$ & $144(44.7)$ & 0.145 & 0.703 \\
\hline$\geq 3$ & $250(45.3)$ & $72(53.3)$ & $178(55.3)$ & & \\
\hline \multicolumn{6}{|c|}{ Lymph node metastasis } \\
\hline Negative & $300(65.7)$ & $106(78.5)$ & $194(60.2)$ & 14.079 & $<0.001$ \\
\hline Positive & $157(34.3)$ & $29(21.5)$ & $128(39.8)$ & & \\
\hline \multicolumn{6}{|l|}{ Status } \\
\hline Censored & $280(61.3)$ & 115 (81.2) & 165 (51.2) & 46.182 & $<0.001$ \\
\hline Death & 177 (34.3) & $20(14.8)$ & $157(48.8)$ & & \\
\hline \multicolumn{6}{|l|}{ Survival time } \\
\hline$\leq 60$ months & $223(48.8)$ & $42(31.1)$ & $181(56.2)$ & 23.985 & $<0.001$ \\
\hline$>60$ months & $234(51.2)$ & $93(68.9)$ & $141(43.8)$ & & \\
\hline
\end{tabular}

ERp29, endoplasmic reticulum protein 29; AJCC, American Joint Committee on Cancer.
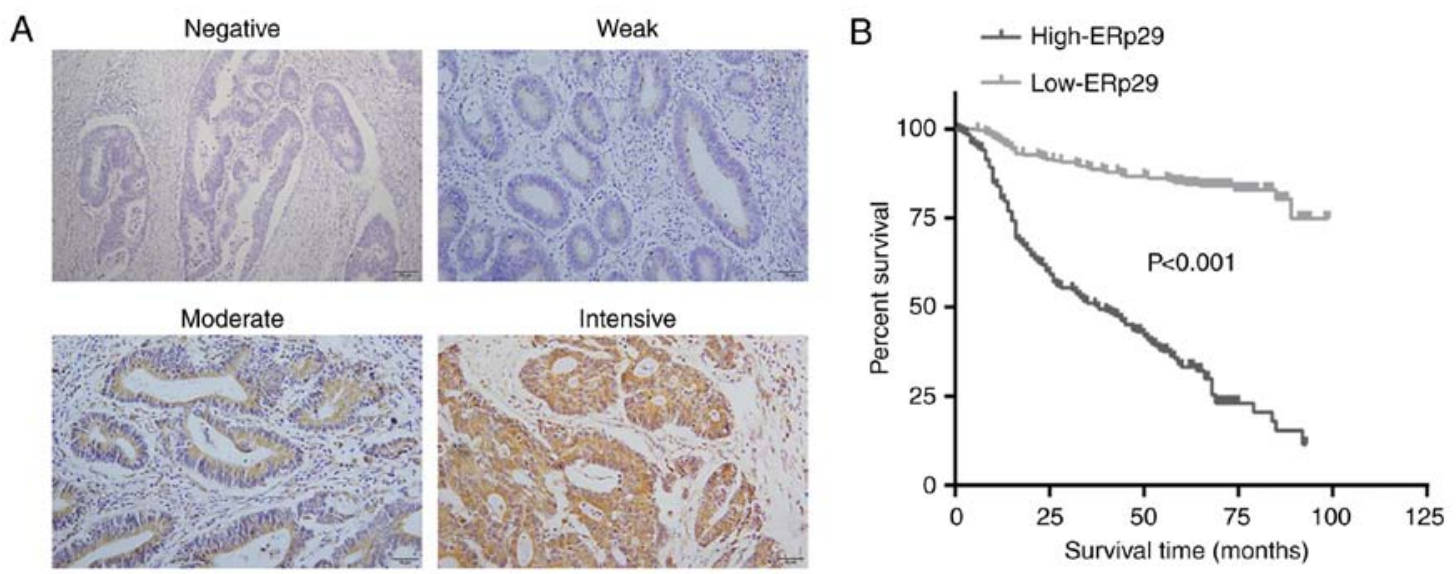

Figure 6. High expression of ERp29 was associated with the poor prognosis of patients with CRC. (A) Immunostaining of ERp29 protein in CRC tissue samples. Scale bar, $50 \mu \mathrm{m}$. (B) Kaplan-Meier survival curve for patients with CRC with ERp29. ERp29, endoplasmic reticulum protein 29; CRC, colorectal cancer.

\section{Discussion}

Stress, any disturbance of the homeostasis of an organism, is a ubiquitous phenomenon shaping life throughout eons of evolution (36). Individuals with malignancy and their cancer cells have to cope with extracellular and intracellular stress (37). ERS is one of the known hemostatic imbalances of bioactivity occurring in an attempt to maintain the functions of 
the cells $(38,39)$. Numerous environmental changes including modifying the canonical protein synthesis machinery may induce cell ERS $(40,41)$. Molecular chaperone proteins function as a protective measure in ERS, and ERp29, a pivotal component, has been associated with cancer of the breast, gallbladder and pancreas (42-44). However, there is little evidence to demonstrate the biological functions of ERp29 in CRC, in particular cancer cells in the state of ERS. A novel observation of the present study was that ERp29 was able to promote CRC cell growth and metastasis by relying on CUL5 during ERS.

In the present study, ERS was constructed using TM, which inhibits the synthesis of products used for glycoprotein chain generation $(45,46)$, and the malignant behaviors, cell growth, migration and metastatic potential of CRC cells were weakened compared with the control. 4-PBA facilitates the handling of mutant proteins and improves protein folding capacity to suppress ERS $(22,47,48)$. When the ERS-state CRC cells were supplemented with 4-PBA in the present study, the malignant behaviors of CRC cells were recovered. The present study established the fundamental model that ERS enables to remodify the biological features of CRC cells, and that neutralizing ERS using 4-PBA may retrieve the decreased malignancy tendency.

ERp29 belongs to the disulfide isomerase-like protein family involved in protein secretion (49). The present study confirmed that ERp29 was involved in CRC cells during ERS, just as ERp29 is harmonious with the ERS of islet beta cells (50). Overexpression of ERp29 in cultured cortical neurons improves neuronal survival and outgrowth following axotomy (51). Downregulation of ERp29 impairs the cell migration of lung adenocarcinoma cells and significantly enhances the chemosensitivity to gemcitabine (52). The present study surveyed the potential function of ERp29 associated with the aggressive behaviors of CRC cells during ERS in vivo and in vitro. Surprisingly, it was revealed that the high expression of ERp29 enhanced cell growth, invasion and experimental metastases in CRC cells during ERS. In other words, ERp29 not only maintains but also enhances sustainable aggressiveness in tumor progression even though the CRC cells are under a state of ERS.

However, it appears to be known that the underlying role of ERp29 is to serve CRC cells during ERS, and CUL5 was identified as a candidate ERp29-modulated protein. Although there exists no evidence to demonstrate whether ERp29 and CUL5 have direct interactions with each other at their specific interactive site, it was revealed that ERp29 needed to be coupled with CUL5 to promote EMT through the detection ofthe markers of EMT in CRC cells during ERS. During CUL5 knockdown, ERp29 was unable to maintain the migration capacity and generate EMT of CRC cells during ERS. Furthermore, clinical tissue examination revealed that the co-expression of ERp29 and CUL5 was positive relative to one another, and the clinicopathological data proved that the high expression of ERp29 was associated with metastasis and the poor prognosis of patients with CRC. Therefore, ERp29 should accompany CUL5 to support malignancy for ERS cancer cells.

In summary, the novel results of the present study are that cancer cells are also able to maintain malignant bioactivities when they encounter disadvantageous stresses, and that ERp29 participates in ERS to counteract the depressed aggressiveness of CRC. Therefore, determining the regulatory mechanism of ERp29 during ERS in CRC progression is meaningful for the diagnosis and treatment of patients with $\mathrm{CRC}$ in advanced stages of the disease.

\section{Acknowledgements}

The authors would like to thank to Professor Yanqing Ding (Southern Medical University, Guangzhou, Guangdong, China) for providing the experimental laboratory site.

\section{Funding}

The present study was supported by the National Key Research and Development Program of China (grant no. 2016YFC1201801), the National Natural Science Foundation of China (grant nos. 81672453, 81372584, 81201970 and 81702359), the Guangdong Provincial Natural Science Foundation of China (grant nos. 2015A030313243, 2015A030310089 and C1051156), the China Postdoctoral Science Foundation (grant no. 2017M622736) and the Guangdong Medical Science and Technology Research Foundation (grant no. A2017403).

\section{Availability of data and materials}

The datasets used and/or analyzed during the current study are available from the corresponding author on reasonable request.

\section{Authors' contributions}

YD, CL and LG conceived and designed the study, wrote, reviewed and edited the manuscript. LM and YL performed the methodological development and analysis of the data. NT and $\mathrm{GH}$ acquired the data. YH, DL and QW collected the data. GL, MT and ZJ performed the animal experiments. All authors read and approved the final manuscript.

\section{Ethics approval and consent to participate}

The patients and/or their relatives provided written informed consent and ethical approval was obtained from the Ethics Committee of Southern Medical University. All animal experiments were approved by the Ethics Committee of Southern Medical University (Guangzhou, China).

\section{Patient consent for publication}

The patients and/or their relatives provided written informed consent for the use of their clinical materials for research purposes.

\section{Competing interests}

The authors declare that they have no competing interests.

\section{References}

1. Araki $\mathrm{K}$ and Nagata K: Prtein folding and quality control in the ER. Cold Spring Harb Perspect Biol 4: a015438, 2012.

2. Oakes SA and Papa FR: The role of endoplasmic reticulum stress in human pathology. Annu Rev Pathol 10: 173-194, 2015. 
3. Navid F and Colbert RA: Causes and consequences of endoplasmic reticulum stress in rheumatic disease. Nat Rev Rheumatol 13: 25-40, 2017.

4. Hotamisligil GS: Role of endoplasmic reticulum stress and c-Jun NH2-terminal kinase pathways in inflammation and origin of obesity and diabetes. Diabetes 54 (Suppl 2): S73-S78, 2005.

5. Thivolet C, Vial G, Cassel R, Rieusset J and Madec AM: Reduction of endoplasmic reticulum-mitochondria interactions in beta cells from patients with type 2 diabetes. PLoS One 12 : e0182027, 2017.

6. Dandekar A, Mendez R and Zhang K: Cross talk between ER stress, oxidative stress, and inflammation in health and disease. Methods Mol Biol 1292: 205-214, 2015.

7. Demmer J, Zhou C and Hubbard MJ: Molecular cloning of ERp29, a novel and widely expressed resident of the endoplasmic reticulum. FEBS Lett 402: 145-150, 1997.

8. Gao D, Bambang IF, Putti TC, Lee YK, Richardson DR and Zhang D: ERp29 induces breast cancer cell growth arrest and survival through modulation of activation of p38 and upregulation of ER stress protein p58IPK. Lab Invest 92: 200-213, 2012.

9. Deng YJ, Tang N, Liu C, Zhang JY, An SL, Peng YL, Ma LL, Li GQ, Jiang Q, Hu CT, et al: CLIC4,ERp29, and Smac/DIABLO derived from metastatic cancer stem-like cells stratify prognostic risks of colorectal cancer. Clin Cancer Res 20: 3809-3817, 2014.

10. Morishima N, Nakanishi K, Takenouchi H, Shibata T and Yasuhiko Y: An endoplasmic reticulum stress-specific caspase cascade in apoptosis. Cytochrome $c$-independent activation of caspase-9 by caspase-12. J Biol Chem 277: 34287-34294, 2002.

11. Han J, Back SH, Hur J, Lin YH, Gildersleeve R, Shan J, Yuan CL, Krokowski D, Wang S, Hatzoglou M, et al: ER-stress-induced transcriptional regulation increases protein synthesis leading to cell death. Nat Cell Biol 15: 481-490, 2013.

12. Nakagawa H, Umemura A, Taniguchi K, Font-Burgada J, Dhar D, Ogata $\mathrm{H}$, Zhong Z, Valasek MA, Seki E, Hidalgo J, et al: ER stress cooperates with hypernutrition to trigger TNF-dependent spontaneous HCC development. Cancer Cell 26: 331-343, 2014.

13. Hsiao JR, Chang KC, Chen CW, Wu SY, Su IJ, Hsu MC, Jin YT, Tsai ST, Takada K and Chang Y: Endoplasmic reticulum stress triggers XBP-1-mediated up-regulation of an EBV oncoprotein in nasopharyngeal carcinoma. Cancer Res 69: 4461-4467, 2009.

14. Hubbard MJ, McHugh NJ and Carne DL: Isolation of ERp29, a novel endoplasmic reticulum protein, from rat enamel cells. Evidence for a unique role in secretory-protein synthesis. Eur J Biochem 267: 1945-1957, 2000.

15. Shnyder SD and Hubbard MJ: ERp29 is a ubiquitous resident of the endoplasmic reticulum with a distinct role in secretory protein production. J Histochem Cytochem 50 $557-566,2002$

16. Hirsch I, Weiwad M, Prell E and Ferrari DM: ERp29 deficiency affects sensitivity to apoptosis via impairment of the ATF6-CHOP pathway of stress response. Apoptosis 19: 801-815, 2014.

17. Zhang D and Putti TC: Over-expression of ERp29 attenuates doxorubicin-induced cell apoptosis through up-regulation of Hsp27 in breast cancer cells. Exp Cell Res 316: 3522-3531, 2010.

18. Qi L, Wu P, Zhang X, Qiu Y, Jiang W, Huang D, Liu Y, Tan P and Tian Y: Inhibiting ERp29 expression enhances radiosensitivity in human nasopharyngeal carcinoma cell lines. Med Oncol 29: 721-728, 2012

19. Zhang B, Wang M, Yang Y, Wang Y, Pang X, Su Y, Wang J, Ai G and Zou Z: ERp29 is a radiation-responsive gene in IEC-6 cell. J Radiat Res 49: 587-596, 2008.

20. Lee DG, Lee SH, Kim JS, Park J, Cho YL, Kim KS, Jo DY, Song IC, Kim N, Yun HJ, et al: Loss of NDRG2 promotes epithelial-mesenchymal transition of gallbladder carcinoma cells through MMP-19-mediated Slug expression. J Hepatol 63 1429-1439, 2015.

21. Reiling JH, Clish CB, Carette JE, Varadarajan M, Brummelkamp TR and Sabatini DM: A haploid genetic screen identifies the major facilitator domain containing 2A (MFSD2A) transporter as a key mediator in the response to tunicamycin. Proc Natl Acad Sci USA 108: 11756-11765, 2011.

22. Kim HJ, Jeong JS, Kim SR, Park SY, Chae HJ and Lee YC: Inhibition of endoplasmic reticulum stress alleviates lipopolysaccharide-induced lung inflammation through modulation of NF-kappaB/HIF-1 $\alpha$ signaling pathway. Sci Rep 3: 1142, 2013.

23. Livak KJ and Schmittgen TD: Analysis of relative gene expression data using real-time quantitative PCR and the 2(-Delta Delta C(T)) method. Methods 25: 402-408, 2001.
24. Thirunavukarasu P, Talati C, Munjal S, Attwood K, Edge SB and Francescutti V: Effect of incorporation of pretreatment serum carcinoembryonic antigen levels into AJCC staging for colon cancer on 5-year survival. JAMA Surg 150: 747-755, 2015.

25. Preissler S, Rato C, Chen R, Antrobus R, Ding S, Fearnley IM and Ron D: AMPylation matches BiP activity to client protein load in the endoplasmic reticulum. Elife 4: e12621, 2015.

26. Eletto D, Dersh D and Argon Y: GRP94 in ER quality control and stress responses. Semin Cell Dev Biol 21: 479-485, 2010.

27. Argon Y and Simen BB: GRP94, an ER chaperone with protein and peptide binding properties. Semin Cell Dev Biol 10: 495-505, 1999.

28. Choi SI, Lee E, Jeong JB, Akuzum B, Maeng YS, Kim TI and Kim EK: 4-Phenylbutyric acid reduces mutant-TGFBIp levels and ER stress through activation of ERAD pathway in corneal fibroblasts of granular corneal dystrophy type 2 . Biochem Biophys Res Commun 477: 841-846, 2016.

29. Krajaejun T, Lohnoo T, Jittorntam P, Srimongkol A, Kumsang Y, Yingyong $\mathrm{W}$, Rujirawat $\mathrm{T}$, Reamtong $\mathrm{O}$ and Mangmee $\mathrm{S}$ : Assessment of matrix-assisted laser desorption ionization-time of flight mass spectrometry for identification and biotyping of the pathogenic oomycete Pythium insidiosum. Int J Infect Dis 77: 61-67, 2018

30. Zhao L, Liu L, Wang S, Zhang YF, Yu L and Ding YQ: Differential proteomic analysis of human colorectal carcinoma cell lines metastasis-associated proteins. J Cancer Res Clin Oncol 133: 771-782, 2007.

31. Kunkler B, Salamango D, DeBruine ZJ, Ploch C, Dean S, Grossens D, Hledin MP, Marquez GA, Madden J, Schnell A, et al: CUL5 is required for thalidomide-dependent inhibition of cellular proliferation. PLoS One 13: e0196760, 2018

32. Lubbers J, Lewis S, Harper E, Hledin MP, Marquez GA, Johnson AE, Graves DR and Burnatowska-Hledin MA: Resveratrol enhances anti-proliferative effect of VACM-1/cul5 in T47D cancer cells. Cell Biol Toxicol 27: 95-105, 2011.

33. Kipreos ET, Lander LE, Wing JP, He WW and Hedgecock EM: cul-1 is required for cell cycle exit in C.elegans and identifies a novel gene family. Cell 85: 829-839, 1996

34. Gao F, Sun X, Wang L, Tang S and Yan C: Downregulation of MicroRNA-145 caused by hepatitis B virus X protein promotes expression of CUL5 and contributes to pathogenesis of hepatitis B virus-associated hepatocellular carcinoma. Cell Physiol Biochem 37: 1547-1559, 2015.

35. Xu XM, Wang XB, Chen MM, Liu T, Li YX, Jia WH, Liu M, Li X and Tang H: MicroRNA-19a and $-19 b$ regulate cervical carcinoma cell proliferation and invasion by targeting CUL5. Cancer Lett 322: 148-158, 2012.

36. Zelenka J, Koncošová M and Ruml T: Targeting of stress response pathways in the prevention and treatment of cancer. Biotechnol Adv 36: 583-602, 2018

37. Northcott JM, Dean IS, Mouw JK and Weaver VM: Feeling stress: The mechanics of cancer progression and aggression. Front Cell Dev Biol 6: 17, 2018.

38. Wang M, Law ME, Castellano RK and Law BK: The unfolded protein response as a target for anticancer therapeutics. Crit Rev Oncol Hematol 127: 66-79, 2018.

39. Hetz C and Papa FR: The unfolded protein response and cell fate control. Mol Cell 69: 169-181, 2018.

40. Schaeffer C, Merella S, Pasqualetto E, Lazarevic D and Rampoldi L: Mutant uromodulin expression leads to altered homeostasis of the endoplasmic reticulum and activates the unfolded protein response. PLoS One 12: e0175970, 2017.

41. Lugea A, Gerloff A, Su HY, Xu Z, Go A, Hu C, French SW, Wilson JS, Apte MV, Waldron RT and Pandol SJ: The combination of alcohol and cigarette smoke induces endoplasmic reticulum stress and cell death in pancreatic acinar cells. Gastroenterology 153: 1674-1686, 2017.

42. Chen S, Zhang Y and Zhang D: Endoplasmic reticulum protein 29 (ERp29) confers radioresistance through the DNA repair gene, $\mathrm{O}(6)$-methylguanine DNA-methyltransferase, in breast cancer cells. Sci Rep 5: 14723, 2015.

43. Yuan LW, Liu DC and Yang ZL: Correlation of S1P1 and ERp29 expression to progression, metastasis, and poor prognosis of gallbladder adenocarcinoma. Hepatobiliary Pancreat Dis Int 12: 189-195, 2013.

44. Zhang K, Yao H, Yang Z, Li D, Yang L, Zou Q, Yuan Y and Miao X: Comparison of ILK and ERP29 expressions in benign and malignant pancreatic lesions and their clinicopathological significances in pancreatic ductal adenocarcinomas. Clin Transl Oncol 18: 352-359, 2016. 
45. Nair S, Xu C, Shen G, Hebbar V, Gopalakrishnan A, Hu R, Jain MR, Liew C, Chan JY and Kong AN: Toxicogenomics of endoplasmic reticulum stress inducer tunicamycin in the small intestine and liver of Nrf2 knockout and C57BL/6J mice. Toxicol Lett 168: 21-39, 2007.

46. Gan PP, Zhou YY, Zhong MZ, Peng Y, Li L and Li JH: Endoplasmic reticulum stress promotes autophagy and apoptosis and reduces chemotherapy resistance in mutant p53 lung cancer cells. Cell Physiol Biochem 44: 133-151, 2017.

47. Yam GH, Gaplovska-Kysela K, Zuber C and Roth J: Sodium 4-phenylbutyrate acts as a chemical chaperone on misfolded myocilin to rescue cells from endoplasmic reticulum stress and apoptosis. Invest Ophthalmol Vis Sci 48: 1683-1690, 2007.

48. Zeng M, Sang W, Chen S, Chen R, Zhang H, Xue F, Li Z, Liu Y, Gong Y, Zhang $\mathrm{H}$ and Kong X: 4-PBA inhibits LPS-induced inflammation through regulating ER stress and autophagy in acute lung injury models. Toxicol Lett 271: 26-37, 2017.

49. Ferrari DM, Nguyen Van P, Kratzin HD and Söling HD: ERp28, a human endoplasmic-reticulum-lumenal protein, is a member of the protein disulfide isomerase family but lacks a CXXC thioredoxin-box motif. Eur J Biochem 255: 570-579, 1998.
50. Gao J, Zhang Y, Wang L, Xia L, Lu M, Zhang B, Chen Y and $\mathrm{He}$ L: Endoplasmic reticulum protein 29 is involved in endoplasmic reticulum stress in islet beta cells. Mol Med Rep 13: 398-402, 2016.

51. Zhang YH, Belegu V, Zou Y, Wang F, Qian BJ, Liu R, Dai P, Zhao W, Gao FB, Wang L, et al: Endoplasmic reticulum protein 29 protects axotomized neurons from apoptosis and promotes neuronal regeneration associated with Erk signal. Mol Neurobiol 52: 522-532, 2015.

52. Ye W, Zhang R, Hu Y, Xu X and Ying K: Increased expression of endoplasmic reticulum protein 29 in lung adenocarcinoma is associated with chemosensitivity to gemcitabine. Anticancer Drugs 26: 612-619, 2015.

This work is licensed under a Creative Commons Attribution-NonCommercial-NoDerivatives 4.0 International (CC BY-NC-ND 4.0) License. 